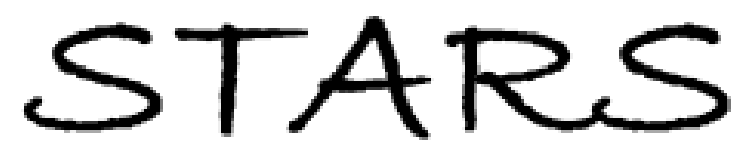

University of Central Florida

STARS

$1-1-2002$

\title{
Correlations between spatially resolved Raman shifts and dislocation density in GaN films
}

\author{
G. Nootz \\ University of Central Florida
}

A. Schulte

University of Central Florida

L. Chernyak

University of Central Florida
A. Osinky
J. Jasinski

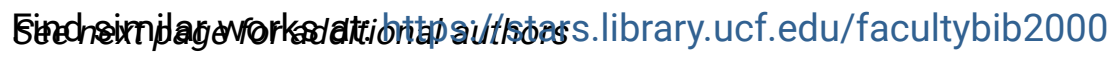

University of Central Florida Libraries http://library.ucf.edu

This Article is brought to you for free and open access by the Faculty Bibliography at STARS. It has been accepted for inclusion in Faculty Bibliography 2000s by an authorized administrator of STARS. For more information, please contactSTARS@ucf.edu.

\section{Recommended Citation}

Nootz, G.; Schulte, A.; Chernyak, L.; Osinky, A.; Jasinski, J.; Benamara, M.; and Liliental-Weber, Z., "Correlations between spatially resolved Raman shifts and dislocation density in GaN films" (2002). Faculty Bibliography 2000s. 3383.

https://stars.library.ucf.edu/facultybib2000/3383

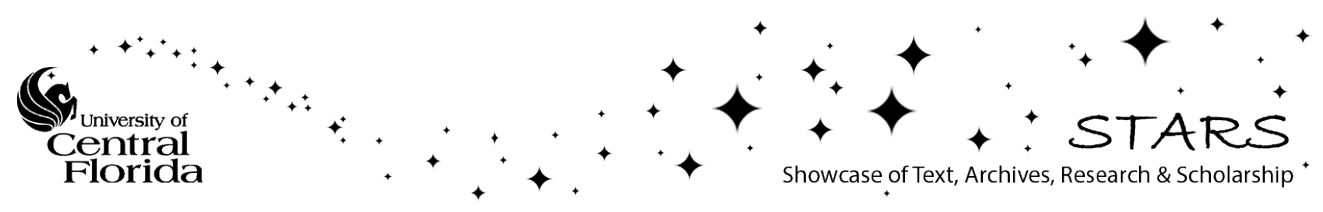


Authors

G. Nootz, A. Schulte, L. Chernyak, A. Osinky, J. Jasinski, M. Benamara, and Z. Liliental-Weber 


\section{Correlations between spatially resolved Raman shifts and dislocation density in GaN films}

Cite as: Appl. Phys. Lett. 80, 1355 (2002); https://doi.org/10.1063/1.1449523

Submitted: 02 July 2001 . Accepted: 19 December 2001 . Published Online: 22 February 2002

G. Nootz, A. Schulte, L. Chernyak, A. Osinsky, J. Jasinski, M. Benamara, and Z. Liliental-Weber

ARTICLES YOU MAY BE INTERESTED IN

Stress and its effect on optical properties of $\mathrm{GaN}$ epilayers grown on $\mathrm{Si}(111), 6 \mathrm{H}-\mathrm{SiC}(0001)$, and c-plane sapphire

Applied Physics Letters 83, 677 (2003); https://doi.org/10.1063/1.1592306

Micro-Raman investigation of strain in $\mathrm{GaN}$ and $\mathrm{Al}_{x} \mathrm{Ga}_{1-\mathrm{X}} \mathrm{N} / \mathrm{GaN}$ heterostructures grown on Si(111)

Journal of Applied Physics 92, 3503 (2002); https://doi.org/10.1063/1.1502921

Raman and cathodoluminescence study of dislocations in GaN

Journal of Applied Physics 92, 6666 (2002); https://doi.org/10.1063/1.1518793

Applied Physics Letters

Mid-IR and THz frequency combs special collection

Read Now! 


\title{
Correlations between spatially resolved Raman shifts and dislocation density in GaN films
}

\author{
G. Nootz, A. Schulte, ${ }^{\text {a) }}$ and L. Chernyak \\ Physics Department, University of Central Florida, Orlando, Florida 32816-2385
}

A. Osinsky
Corning Applied Technologies, Woburn, Massachusetts 01801

J. Jasinski, ${ }^{\text {b) }}$ M. Benamara, and Z. Liliental-Weber

Lawrence Berkeley National Laboratory, Berkeley, California 94720

(Received 2 July 2001; accepted for publication 19 December 2001)

\begin{abstract}
Spatially resolved Raman spectra were measured on thick GaN samples with known dislocation density grown by hydride vapor phase epitaxy. The frequencies of the $E_{2}$ (high) and $E_{1}$ (transverse optical) phonons shift to lower wave number over a distance of $30 \mu \mathrm{m}$ from the sapphire substrate/ $\mathrm{GaN}$ interface. The shifts are linearly correlated with the dislocation density suggesting that the strain due to the lattice mismatch at the interface determines both quantities. (C) 2002 American Institute of Physics. [DOI: 10.1063/1.1449523]
\end{abstract}

One of the key issues for the performance of GaN based device structures is the control of growth-induced defects and their impact on optoelectronic and transport properties. Despite the impressive progress in device applications a deeper understanding of defect and impurity issues is necessary for continued rapid development in the areas of light emitting and laser diodes, ultraviolet detectors, and high voltage unipolar and bipolar devices. ${ }^{1}$ Raman spectroscopy has proven to be an informative and nondestructive technique in III-V material characterization including local structure determination and stress analysis. ${ }^{2}$ In low temperature, spatially resolved measurements shifts in the luminescence band and the $E_{2}$ Raman mode have been observed with decreasing distance to the substrate interface. ${ }^{3}$ These were attributed to vertical strain and doping gradients. In a highly $\mathrm{Si}$ doped GaN material the quenching of the $A_{1} \mathrm{Ra}-$ man line by donor impurities has been used to image spatially varying carrier concentrations in faceted $\mathrm{GaN}$ crystallites. ${ }^{4}$ In quasibulk $n$-type $\mathrm{GaN}$ electron beam and optical depth profiling has recently been employed to measure the minority hole diffusion length as a function of distance from the GaN/sapphire substrate interface. ${ }^{5}$ The observed decrease in photoluminescence intensity and minority carrier diffusion length with decreasing distance from the interface was attributed to reduced carrier mobility and lifetime at the interface, due to scattering at threading dislocations. To relate strains present in the material due to a GaN/sapphire lattice mismatch we have performed spatially resolved Raman measurements and correlated them with dislocation density. The $E_{2}$ (high) and $E_{1}$ transverse optical (TO) phonons show shifts toward higher frequencies at the GaN/sapphire interface, which are linearly related with a spatial variation in dislocation density.

The samples under investigations were grown at the MIT

\footnotetext{
a) Author to whom correspondence should be addressed; electronic mail: afs@physics.ucf.edu

b) On leave from Institute of Experimental Physics, Warsaw University, 69 Hoza Str., 00-681 Warsaw, Poland.
}

Lincoln Laboratory by hydride vapor phase epitaxy. ${ }^{6}$ Several different films with thickness from 36 to $64 \mu \mathrm{m}$ were used in our experiments. Room-temperature Hall measurements showed $n$-type electrical conductivity for these samples, with electron concentrations (at the surface) ranging from 8 $\times 10^{16}$ to $1.2 \times 10^{17} \mathrm{~cm}^{-3}$, and mobilities of $580-750$ $\mathrm{cm}^{2} / \mathrm{V} \mathrm{s}$, respectively. The samples were then cleaved, to obtain a surface perpendicular to the growing direction on which the investigation could be made.

Raman spectra were measured with a single-grating spectrometer (HR 640, Instruments SA) equipped with a thinned back-illuminated charge-coupled device (CCD) detector (TKB 1024, Princeton Instruments) and a homebuilt microattachment. A holographic notch filter rejected the Rayleigh line. Raman scattering was excited with the $514.53 \mathrm{~nm}$ line of an $\mathrm{Ar}^{+}$ion laser at a power of $10 \mathrm{~mW}$. An infinity corrected microscope objective focused the laser beam to a spot size of about $1 \mu \mathrm{m}$ in diameter. Due to the high sensitivity of the Raman system a very narrow entrance slit of the spectrometer $(5 \mu \mathrm{m})$ was employed, and the spectra were measured in the second order of the diffracted light. The acquisition time of individual spectra was less than $30 \mathrm{~s}$ at a spectral resolution of $1 \mathrm{~cm}^{-1}$. During the entire experiment the drive of the spectrometer was not moved to avoid drifts of the wavelength position. The narrow slit and binning the CCD chip in the vertical direction effectively provided a confocal aperture and 1-2 $\mu \mathrm{m}$ depth resolution. The excitation beam was parallel to the surface of the interface and therefore perpendicular to the growth direction of the GaN layers. Sample positioning was performed with a translation stage allowing submicron increments.

Figure 1 presents the Raman spectra at various distances from the GaN/sapphire interface over a range of $64 \mu \mathrm{m}$. The data were collected with a backscattering geometry. The propagation direction of the laser beam was perpendicular to the $c$ axis, but not along one of the principle axes so the $A_{1}(\mathrm{TO}), E_{1}(\mathrm{TO}), E_{1}$ longitudinal optical (LO), and $E_{2}$ (high) modes are observed at 532, 558, 744, and $567 \mathrm{~cm}^{-1}$, respec- 


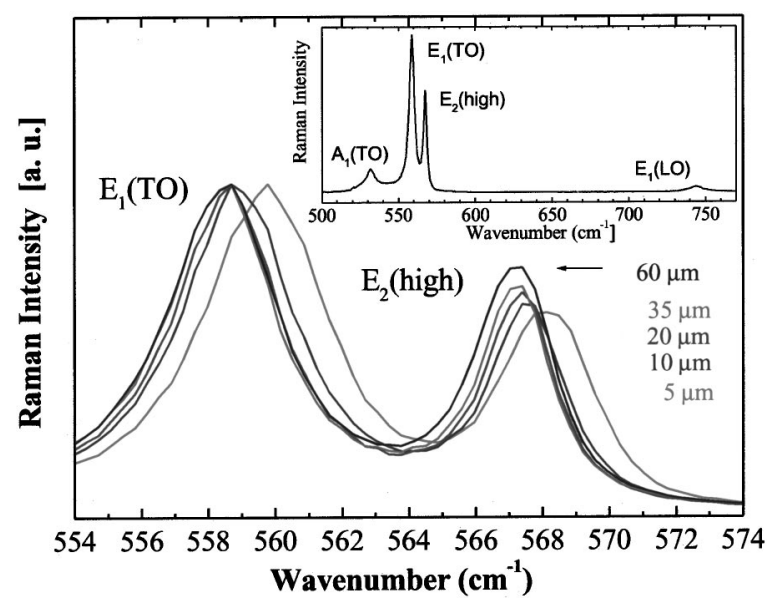

FIG. 1. Raman spectra of a $64 \mu \mathrm{m}$ thick GaN film measured with $514.5 \mathrm{~nm}$ excitation. Inset shows $E_{1}(\mathrm{TO})$ and $E_{2}(\mathrm{high})$ modes for various distances from the $\mathrm{GaN}$ interface.

tively. These frequencies are measured $60 \mu \mathrm{m}$ away from the interface and are in good agreement with literature data. ${ }^{2}$ Due to limitations of the Rayleigh filter the $E_{2}($ low $)$ mode $\left(144 \mathrm{~cm}^{-1}\right)$ was not investigated. The raw data presented in Fig. 1 show a shift of the $\mathrm{E}_{1}(\mathrm{TO})$ and $E_{2}$ (high) modes to higher frequency with decreasing distance from the sapphire substrate. We did not observe any significant changes in full width at half maximum of the spectral bands. The precision in the determination of the frequency shifts could be further increased by fitting Lorenzian lines to the Raman peaks. Since the line shape remains constant we estimate that spectral shifts of $0.1 \mathrm{~cm}^{-1}$ can be reliably detected. ${ }^{7}$

The peak frequencies of the Raman modes are shown as a function of the distance from the GaN/sapphire interface in Fig. 2. The shift of the $E_{2}$ (high) and $E_{1}(\mathrm{TO})$ phonons to higher energy when approaching the GaN/sapphire interface is clearly visible for measurements in both directions, i.e.,

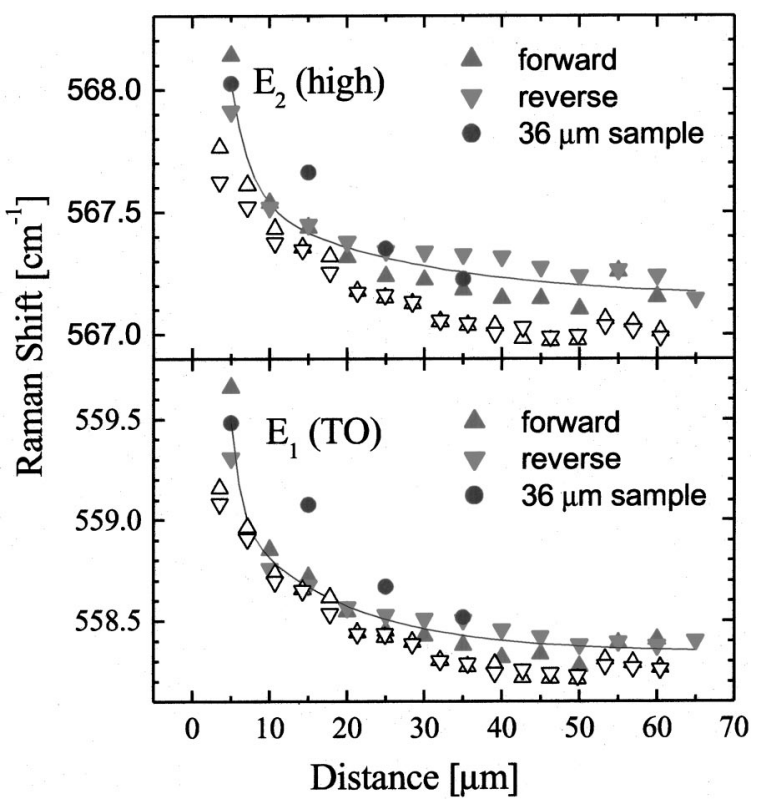

FIG. 2. Peak frequencies of the Raman $E_{2}$ (high) and $E_{1}(\mathrm{TO})$ modes as a function of distance to the substrate interface. The solid lines represent exponential fits to the data points with asymptotic values of 567.2 and 558.3 $\mathrm{cm}^{-1}$, respectively. The open symbols show results from a second experiment on a sample grown under the same conditions.

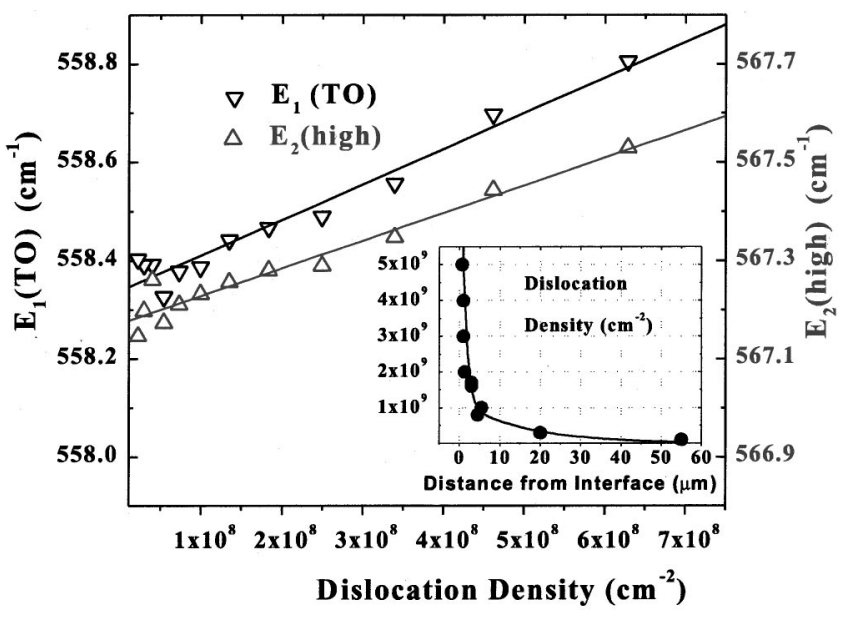

FIG. 3. Correlation between peak position of the $E_{1}(\mathrm{TO})$ and $E_{2}(\mathrm{high})$ Raman modes and dislocation density. Data from two different samples (64 and $36 \mu \mathrm{m}$ thick) are shown.

from the interface to the surface and backward. In addition, an independent experiment was conducted with another sample from the same batch. The shifts of the frequencies with distance are very reproducible; a small difference $(0.2$ $\mathrm{cm}^{-1}$ ) in the absolute wave number is within the error of the calibration. The $E_{2}$ Raman mode is known to be affected by stress. ${ }^{8-11}$ In GaN films large compressive stresses causing frequency shifts of $+4.5 \mathrm{~cm}^{-1}$ compared to single crystals have been observed. ${ }^{9}$ The small changes in the $E_{2}$ (high) and $E_{1}(\mathrm{TO})$ modes, presented here, indicate the good quality of our films. Approximating the zero-stress $E_{2}$ phonon frequency by the value measured far from the interface (567.2 $\mathrm{cm}^{-1}$ ) we find a strain induced shift of $+1 \mathrm{~cm}^{-1}$. This corresponds to a compressive strain of $0.42 \mathrm{GPa}$ within $5 \mu \mathrm{m}$ of the $\mathrm{GaN} / \mathrm{sapphire}$ interface based on the stress determination in Ref. 9. The absence of a significant shift in the $A_{1}$ phonon may be related to the direction of the optical phonon eigenvectors with respect to the $c$ axis. Among the Raman active modes $A_{1}$ is the only one with displacements along the $c$ axis $^{12,2}$ as opposed to the $E_{2}$ (high) and $E_{1}(\mathrm{TO})$ vibrations.

Figure 3 presents the correlation between the peak frequencies of the $E_{2}$ and $E_{1}$ Raman modes and the dislocation density. Data for the dislocation density as a function of distance from the sapphire/GaN interface were obtained from transmission electron microscope (TEM) measurements. ${ }^{5}$ The two phonon frequencies depend linearly on the dislocation density over an order of magnitude range. The average dislocation distance calculated from the density varies from 0.35 to $0.69 \mu \mathrm{m}$ at a distance of $8-32 \mu \mathrm{m}$ from the interface, respectively. A similar shift in the $E_{2}$ Raman mode has been reported in Ref. 3 and been attributed to vertical strain. In the films discussed here, shifts are not only observed for the $E_{2}$ (high) but also for the $E_{1}(\mathrm{TO})$ mode. These as well as the linear correlation with dislocation density may be attributed to the biaxial strain due to lattice mismatch of the sapphire substrate. The same biaxial strain is responsible for the formation and multiplication of dislocations near the interface during film growth. The local strain associated with dislocations (and thus a direct relationship) is more complex, because it depends on the particular arrangement of dislocations and involves both tensile compressure and shear 
components. The strain is extremely high near the core of the dislocation but decreases with the square of the distance away from the core.

We note that the shifts, observed in Fig. 2 for the $E_{2}$ (high) and $E_{1}(\mathrm{TO})$ modes may be related to the directions of the vibrational displacements of the $\mathrm{Ga}$ and $\mathrm{N}$ atoms relative to the threading dislocations. Both displacements are perpendicular to the $c$ axis of the wurzite $\mathrm{GaN}$ lattice and also to the direction of threading dislocations propagation. Wu et al. ${ }^{13}$ have shown that above $\sim 0.5 \mu \mathrm{m}$ to the film free surface the threading dislocations are straight and show little interaction with most of the threading segments being perpendicular to the surface. Larger Raman shifts are indeed observed in regions at higher dislocation density and for the $E_{2}$ (high) and $E_{1}(\mathrm{TO})$ modes. A less pronounced shift for the $A_{1}$ (TO) mode with eigenvectors parallel to the $c$ axis is also consistent. On the other hand, we did not find significant shifts of the $E_{1}(\mathrm{LO})$ mode although the displacement vectors are perpendicular to the $c$ axis. The reason is not clear at the present time and may lie in the more complex local strains.

In summary, micro-Raman spectroscopy shows a high frequency shift for the $E_{2}$ (high) and $E_{1}$ optical phonons at the GaN/sapphire interface. We were able to correlate independently obtained data on dislocation density and vibrational modes which are connected to the strain due to lattice mismatch at the interface.

The authors would like acknowledge financial support from the University of Central Florida through the Presidential equipment initiative program. R. J. Molnar (Lincoln Lab) and D. C. Look (AFRL) are acknowledged for providing bulk GaN samples. The TEM group (J.J., M.B., and Z.L.-W.) acknowledges financial support from the Air Force Office of Scientific Research, through the U.S. Department of Energy under Order No. AFOSR-ISSA-00-0011, and thanks W. Swider for her excellent TEM sample preparation and NCEM in Berkeley for the use of TEM facility.

${ }^{1}$ S. J. Pearton, J. C. Zoiper, R. J. Shul, and F. Ren, J. Appl. Phys. 86, 1 (1999).

${ }^{2}$ L. Bergman, M. Dutta, and R. J. Nemanich, in Raman Scattering in Materials Science, edited by W. H. Weber and R. Merling (Springer, Berlin, 2000).

${ }^{3}$ H. Siegle, A. Hoffmann, L. Eckey, C. Thomsen, J. Christen, F. Bertram, D. Schmidt, D. Rudloff, and K. Hiramatsu, Appl. Phys. Lett. 71, 2490 (1997).

${ }^{4}$ F. A. Ponce, J. W. Steeds, C. D. Dyer, and G. D. Pitt, Appl. Phys. Lett. 69, 2650 (1996).

${ }^{5}$ L. Chernyak, A. Osinsky, G. Nootz, A. Schulte, J. Jasinski, M. Benamara, Z. Liliental-Weber, D. C. Look, and R. J. Molnar, Appl. Phys. Lett. 77, 2695 (2000).

${ }^{6}$ R. J. Molnar, W. Götz, L. T. Romano, and N. M. Johnson, J. Cryst. Growth 178, 147 (1997).

${ }^{7}$ D. L. Rousseau, J. Raman Spectrosc. 10, 94 (1981).

${ }^{8}$ P. Perlin, C. Jauberbie-Carillon, J. P. Itie, A. S. Miguel, I. Grzegory, and A. Polian, Phys. Rev. B 45, 83 (1992).

${ }^{9}$ C. Kisielowski, J. Krueger, S. Ravimov, T. Suski, J. W. Ager III, E. Jones, Z. Liliental-Weber, M. Rubin, E. R. Weber, M. D. Bremser, and R. F. Davis, Phys. Rev. B 54, 17745 (1996).

${ }^{10}$ M. Seon, T. Prokofyeva, M. Holtz, S. A. Nikishin, N. N. Faleev, and H. Temkin, Appl. Phys. Lett. 76, 1842 (2000).

${ }^{11}$ T. Prokofyeva, M. Seon, J. Vanbuskirk, M. Holtz, S. A. Nikishin, N. N. Faleev, H. Temkin, and S. Zollner, Phys. Rev. B 63, 125313 (2001).

${ }^{12}$ J. M. Zhang, T. Ruf, M. Cardona, O. Ambacher, M. Stutzmann, J.-M. Wagner, and F. Bechstedt, Phys. Rev. B 56, 14399 (1997).

${ }^{13}$ X. H. Wu, L. M. Brown, D. Kapolnek, S. Keller, B. Keller, S. P. DenBaars, and J. S. Speck, J. Appl. Phys. 80, 3228 (1996). 